\title{
PREDICTION OF HIGH-LIFT FLOWS USING TURBULENT CLOSURE MODELS
}

\author{
Christopher L. Rumsey, ${ }^{\text {a,* }}$ Thomas B. Gatski, ${ }^{a}$ Susan X. Ying, ${ }^{\text {b** }}$ and Arild Bertelrud ${ }^{c, *}$ \\ ${ }^{a}$ NASA Langley Research Center, Mail Stop 128, Hampton, VA 23681-0001, b McDonnell Douglas Corporation, \\ Long Beach, CA, and ${ }^{\mathrm{c}}$ Analytical Services and Materials, Inc., Hampton, VA
}

\begin{abstract}
The flow over two different multi-element airfoil configurations is computed using linear eddy viscosity turbulence models and a nonlinear explicit algebraic stress model. A subset of recently-measured transition locations using hot film on a McDonnell Douglas configuration is presented, and the effect of transition location on the computed solutions is explored. Deficiencies in wake profile computations are found to be attributable in large part to poor boundary layer prediction on the generating element, and not necessarily inadequate turbulence modeling in the wake. Using measured transition locations for the main element improves the prediction of its boundary layer thickness, skin friction, and wake profile shape. However, using measured transition locations on the slat still yields poor slat wake predictions. The computation of the slat flow field represents a key roadblock to successful predictions of multi-element flows. In general, the nonlinear explicit algebraic stress turbulence model gives very similar results to the linear eddy viscosity models.
\end{abstract}

\section{INTRODUCTION}

\subsection{Overview}

The prediction of high-lift (multi-element airfoil) flow fields currently represents a difficult challenge for the computational fluid dynamics (CFD) and turbulence modeling community. Even in two dimensions, state-ofthe-art CFD codes fail to predict trends with Reynolds number or trends with flap/slat rigging changes sufficiently accurately. ${ }^{1}$ Without the capability to consistently predict trends using CFD, aircraft designers must rely on heuristic techniques and wind-tunnel experiments, which themselves present additional difficulties when attempting to scale the results up to flight Reynolds numbers. ${ }^{2,3,4}$

The flow around a multi-element airfoil or wing is inherently complex. Variations in angle of attack and different slat / flap settings often present very different and distinct challenges. For example, for typical landing configurations, viscous effects can dominate compressibility effects near stall, whereas for typical take-off configurations compressibility can dominate the stall physics. ${ }^{5}$ Also, flap separation is often seen at low to moderate angles of attack, whereas stall is often caused by an unloading of the aft portion of the main element due to rapidly spreading and merging shear layers and wakes over the flap.

Although high-lift devices work essentially because they manipulate the inviscid flow, ${ }^{2}$ viscous effects are crucial as well. According to Meredith, ${ }^{6}$ some of the viscous features that can affect 2D multi-element systems

\footnotetext{
*Senior Member AIAA.
}

Copyright (- 1997 by the American Institute of Aeronautics and Astronautics, Inc. No copyright is asserted in the United States under Title 17, U.S. Code. The U.S. Government has a royalty-free license to exercise all rights under the copyright claimed herein for Governmental purposes. All other rights are reserved by the copyright owner. include: (1) boundary layer transition, (2) shock/boundary layer interactions, (3) viscous wake interactions, (4) confluent wakes and boundary layers, and (5) separated flows. Some important insights into the physical processes that govern high-lift aerodynamics were summarized by A. M. O. Smith in his landmark 1975 paper. ${ }^{7}$ In particular, he described several effects that contribute to improved high-lift characteristics of multiple elements over single elements.

A great body of work on high-lift flows, both experimental and computational, has built up since that time. (See, for example, discussions in the papers by Lynch et al, ${ }^{1}$ Haines, ${ }^{2}$ Woodward and Lean, ${ }^{8}$ Thibert et al, ${ }^{9}$ Valarezo, ${ }^{10}$ and Ying. ${ }^{5}$ ) Some experiments have been performed expressly for the purpose of CFD code validation. For example, an AGARD three-element take-off configuration, tested in the early 1970's and subsequently used as a part of a battery of AGARD test cases, ${ }^{11}$ was recently used as a code validation challenge ${ }^{12}$ by the CFD Society of Canada. Experiments have also been performed in the NASA Langley Low Turbulence Pressure Tunnel (LTPT) ${ }^{13,14}$ on McDonnell Douglas three-element landing configurations, used as test cases in a CFD Challenge Workshop held at NASA Langley in 1993. Several papers have been written that describe various aspects of experimental testing on these configurations.

Since the CFD Challenge Workshop, there have been many CFD results reported for the McDonnell Douglas three-element configurations, using a variety of numerical schemes for the Navier-Stokes equations. The incompressible Navier-Stokes code INS2D, using both point-matched and overset grids, has been used extensively to assess the ability of CFD to model trends with configuration changes, as well as to assess the effects of tunnel walls, grid density, and turbulence model. ${ }^{20-22}$ It has also been coupled with a transition-prediction methodology. ${ }^{23}$ Compressible Navier-Stokes codes have been used as well. Jones et al ${ }^{24}$ used the CFL3D code with overset grids to compute flow over both the 2D McDonnell Douglas three-element configurations as 
well as 3D flow over wings with flaps. The structured grid codes OVERFLOW and TLNS3D and the unstructured-grid codes NSU2D and FUN2D have also been applied to the 2D McDonnell Douglas configura-

\subsection{Code Validation Issues}

Overall, CFD comparisons with experiment for the 2D McDonnell Douglas three-element configurations have been somewhat ambiguous. Considering the inherent complexity of the flow field, CFD results are surprisingly good, particularly with regard to surface pressures. Unfortunately, the trends with Reynolds number and configuration changes are not accurate enough to meet the needs of wing designers, and the maximum lift coefficient and the angle of attack at which it occurs tend to be overpredicted. ${ }^{\mathrm{T}}$ However, it is still not clear at this time whether the fault is due to (1) inadequate modeling in the CFD (turbulence models, transition models), and/ or (2) the fact that CFD is not simulating the same configuration as experiment.

The former possibility may play a role because turbulence models vary in the accuracy to which they predict free shear flow behavior (such as spreading rate), and most in use today are eddy-viscosity one- and two-equation models that do not account for curvature effects or anisotropy. It is possible that some missing effects such as these may be important in certain regions of multi-element flow fields. Additionally, most CFD codes prescribe rather than predict transition locations; these locations can have a significant effect on the solution. ${ }^{27,28}$ Moreover, the transition process itself is usually not modeled. Instead, the eddy viscosity is generally "switched on" at transition points. More sophisticated transition models, such as that employed by $\mathrm{Cebeci}^{29}$ (in an interactive boundary layer code coupled with an algebraic turbulence model), are currently not in wide use. The presence of laminar separations bubbles, which are usually associated with high peak suctions and steep adverse pressure gradients, counted for.

The latter possibility - that CFD may not be simulating the same configurations as experiment - arises particularly because of questions regarding deviation from two-dimensionality in experimental tests and the applicability of 2D CFD simulations to such flows. Additionally, the effects of surface roughness, tunnel turbulence, external tunnel devices, and structural model deformations need to be considered. Since multi-element airfoil flow appears to be very sensitive to all of these parameters, it is often difficult to determine precisely why a CFD simulation is in error from a given experimental result. As an example of the experimental sensitivity, a three-element airfoil section representing the section at $59 \%$ span of the $\mathrm{A} 310$ wing was found to give a negative trend of $C_{L m a x}$ with Reynolds number between 6 million and 16 million for an unpolished model, but a positive trend when the model was polished. ${ }^{30}$

\subsection{Turbulence Model Studies}

Rogers et $\mathrm{al}^{31}$ has shown that several different eddyviscosity models tend to be consistent in their prediction of the flow over the McDonnell Douglas three-element configuration. The differences between the turbulence models are generally smaller than the differences between computation and experiment. Some further perspective may be gained on the issue of turbulence modeling by considering other experimental and computational results for different configurations. Squire ${ }^{32}$ and Agoropoulos and Squire ${ }^{33}$ compared computed velocity profiles and turbulence quantities with experimental results over a two-element model designed to explore slat-wake / main-wing-boundary-layer interaction. They describe the merging process by three regimes: (1) unmerged, when the wake and boundary layer are separated by a potential core, (2) initial merging, when the outer part of the wake and inner part of the boundary layer are unaffected, and (3) full merging resulting in a new, thicker boundary layer (although full merging usually does not occur prior to the main element trailing edge.) Using the incompressible NavierStokes equations with a $k-\varepsilon$ turbulence model and an algebraic stress model (ASM), they found good agreement between both models and experiment in the initial stages of the merging, with somewhat better results using the ASM. Decelerated flows were predicted with the same accuracy as those in constant pressure. Squire also discussed the fact that stress transport models often predict too rapid a relaxation of the flow following disturbances since model constants are generally weighted toward equilibrium flows. This results in a too rapid disappearance of the velocity defect in the wake, as well as of the corresponding shear stress peaks.

In addition to computing the CFD Challenge Workshop landing configurations, Anderson and Bonhaus ${ }^{34}$ computed the flow over a McDonnell Douglas three-element take-off configuration with the unstructured code FUN2D. They compared with the experimental results of Nakayama et al, ${ }^{33}$ including turbulent shear stress data. Using the one-equation eddy-viscosity turbulence model of Spalart and Allmaras, ${ }^{36}$ turbulent shear stress profiles were found to be in overall reasonable agreement with the experiment. Peak levels were underpredicted on the flap, but results in that region may not have been sufficiently grid-converged.

Lien and Leschziner ${ }^{37}$ and Lien et $\mathrm{al}^{38}$ computed the flow over both a separated single-element ONERA airfoil as well as a two-element (main element and flap) NLR-7301 airfoil. ${ }^{39}$ They compared results using $k-\varepsilon$ two-equation eddy-viscosity models with full secondmoment Reynolds stress closure models on the ONERA airfoil, and found that the latter models are generally superior. However, all of the turbulence models performed poorly in the far wake, in regions where the turbulence production over dissipation is low. The $k-\varepsilon$ eddy-viscosity model performed fairly well on the NLR-7301 airfoil, although wake mixing was incorrect and there was insufficient mixing between the wing wake and flap boundary layer. This was attributed to the inability of the $k-\varepsilon$ model to represent curvature-turbulence interaction.

Godin et $\mathrm{al}^{40}$ also computed the flow over the NLR7301 airfoil, using the one- and two-equation eddy-viscosity turbulence models of Spalart and Allmaras ${ }^{36}$ (SA) and Menter ${ }^{41}$ (SST). They found good agreement in general with both models, although the SST model tended to be more accurate in separated flow regions while the S-A model performed better in attached flows and wakes, including the merging wake / boundary layer re- 
gion. Turbulent shear stress profiles appeared to agree better in general with experiment than the results of Lien et $\mathrm{al}^{38}$ using the $k-\varepsilon$ eddy-viscosity model, but velocity profiles were similar. Cao and Kusunose, ${ }^{27}$ Jasper et al, $^{42}$ and Fritz ${ }^{43}$ also computed this $2 \mathrm{D}$ flow, using various zero-, one-, and two-equation eddy-viscosity models. Generally positive agreement with experimental data was obtained for lift, surface pressures, and velocity profiles, although the zero-equation (algebraic) model used in Jasper et al resulted in poorer predictions of boundary layer parameters and stall onset compared with a one-equation model. No comparisons with Reynolds stress data were made in these three references.

The results for the NLR-7301 airfoil seem to support the finding of Rogers et $\mathrm{al}^{31}$ (for the McDonnell-Douglas configuration) that, while there are certainly noticeable differences at a detailed level, many eddy-viscosity turbulence models overall tend to have only relatively minor effects on global properties for multi-element airfoil predictions. (This conclusion is of course dependent on particulars of the flow field in question. For example, for flows with boundary layer separation, models such as S-A and SST have been shown to be superior to the "standard" Jones-Launder version of $k-\varepsilon .^{41,44}$ ) The question of whether more advanced nonlinear turbulence models would produce significantly better results for multi-element airfoils remains open.

\subsection{Focus of this Paper}

Because of the complexity and interdependence of many factors in high-lift computing and experimentation, it seems inappropriate to focus solely on the subject of turbulence modeling without regard for other factors. We therefore take a somewhat broader approach. The purpose of this paper is to contribute to a greater understanding of issues surrounding CFD validation against high-lift wind tunnel tests. As a consequence, it focuses both on experimental as well as numerical issues. Specifically, the purpose is threefold: (1) introduce a subset of transition locations for the 2D McDonnell Douglas three-element configuration recently measured in the LTPT with hot film, (2) demonstrate the effect of transition location on CFD solutions, and (3) explore the effect of a nonlinear explicit algebraic Reynolds stress turbulence model ${ }^{45}$ on the CFD solution for both the AGARD take-off configuration 11,12 and the McDonnell Douglas landing configuration. ${ }^{15-19}$ It is hoped that by taking this approach, we can not only determine the impact of modeling the nonlinear Reynolds stress terms, but also demonstrate the importance (and difficulty!) of accurately modeling the wind tunnel experiment, particularly with regard to the transition process.

\section{DESCRIPTION OF THE AIRFOIL CONFIGURATIONS AND CFD GRIDS}

Two multi-element configurations are investigated in this paper. Both employ one-to-one point connectivity across grid zones. Grids with one-to-one point connectivity insure conservation across boundaries and provide improved continuity of grid spacing at zonal interfaces, although this type of grid generation is substantially more difficult than for overset grids.

Only fine grids are employed, since extensive grid sensitivity studies have been published previously for both the CFL3D $\operatorname{code}^{24}$ as well as for other codes $^{20,21,22,26}$ over similar configurations. These studies indicate that velocity profiles are more sensitive to grid density than surface pressures and lift coefficient. When between $100,000-200,000$ grid points are used for point-matched grids similar to the grids used in the current study, further refinement yields only minor differences in the computed velocity profiles. ${ }^{22}$ These earlier studies also indicate the importance of having sufficient resolution in the wakes and boundary layers. The grids used in the current study have over 100,000 grid points with minimum normal wall grid spacings that yield an average $y+$ of approximately $0.3-0.4$ for their respective free stream Reynolds numbers. The grids are also clustered in the wake regions of each element.

The first case is a three-element configuration defined as case A2 in a battery of AGARD test cases ${ }^{11}$ and used as a test case for the code validation challenge ${ }^{12}$ by the CFD Society of Canada in June 1996. Although tested in a wind tunnel with solid walls, the AGARD test case is performed on a "free air" grid with far field extent of about 10 chords. (The original model has a stowed chord of $c=0.7635 \mathrm{~m}$, and the tunnel height to chord ratio is $H / c=5.19$.) The slat is positioned at an angle of $25^{\circ}$, while the single-slotted flap has a moderate deflection angle of $20^{\circ}$, typical of a take-off configuration. A closeup of the grid used for this case is shown in figure 1. This is a 4-zone grid with 114,908 grid points. The abscissa of this figure is given in terms of $x / c$, and the stowed airfoil would have its leading and trailing edges at $x / c$ of 0 and 1 , respectively. This configuration is computed at $M=0.197$ and $R e=3.52 \times 10^{6}$ based on stowed-geometry chord. Transition is tripped on the main element at $x / c=0.125$ on both the upper and lower surface, and is free on the slat and flap.

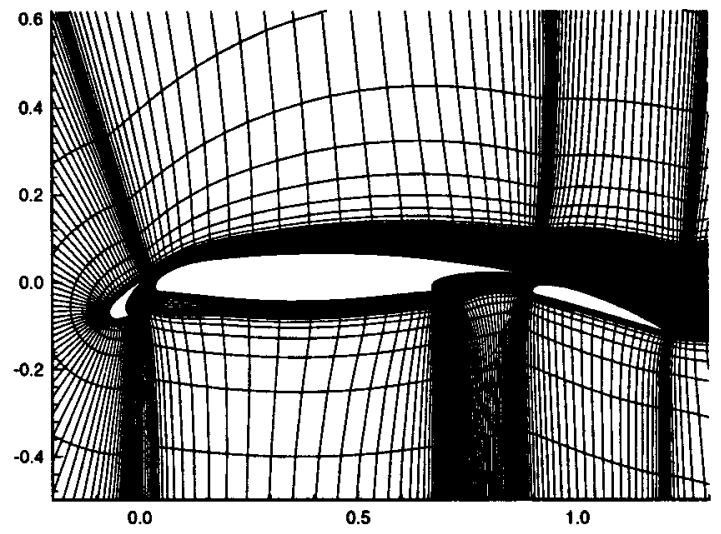

Fig. 1. AGARD configuration grid, with every other grid point removed.

The second configuration is a three-element McDonnell Douglas configuration, ${ }^{15-19}$ tested in the LTPT and used as a test case in a CFD Challenge Workshop held at NASA Langley in 1993. The model has a stowed chord of $c=0.5588 \mathrm{~m}$ and the tunnel height is 
$H / c=4.09$. The particular slat and flap settings employed are: slat deflection of $30^{\circ}$, slat gap of $2.95 \%$, slat overhang of $-2.5 \%$, flap deflection of $30^{\circ}$, flap gap of $1.27 \%$, and flap overhang of $0.25 \%$. This rigging designation is referred to as $30 \mathrm{P}-30 \mathrm{~N}$. It is typical of a landing configuration. It is computed using both a "free air" grid with far field extent of about $15 c$, as well as a grid that models an angle of incidence of $19^{\circ}$ with LTPT walls. This latter grid extends $15 c$ upstream and $19 c$ downstream of the model to avoid the possibility of inflow / outflow boundary influence on the solution, although the actual LTPT test section does not extend this far. A close-up of this latter grid is shown in figure 2. This is a 5 -zone grid with 138,389 grid points. It is computed at $M=0.2$ and $R e=9 \times 10^{8}$ based on stowed-geometry chord. In the wind tunnel test, transition is free on each of the elements.

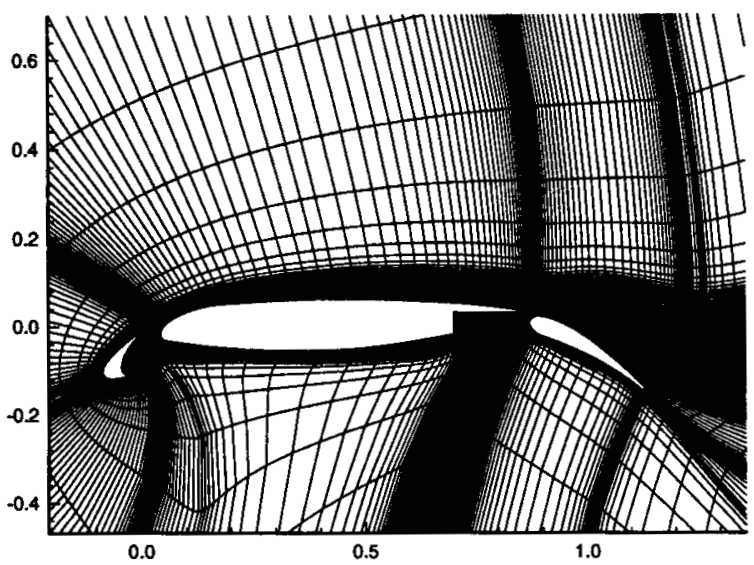

Fig. 2. McDonnell Douglas 30P-30N grid, with every other grid point removed.

\section{DESCRIPTION OF THE TRANSITION TEST AND DATA}

A subset of transition data recently taken in the LTPT is presented here for the McDonnell Douglas three-element configuration. The hot-film sensors are similar to those used by Nakayama et al $^{46}$ for a similar configuration in the same wind tunnel. They are thin nickel films on a $0.05 \mathrm{~mm}$ polyimide substrate. The sensors are arranged in a straight streamwise array at $73.4 \%$ span, whereas most pressure taps are located at $50 \%$ span. Side-wall suction is used to maintain approximate twodimensionality for the flow. However, this is optimized for $16^{\circ}$ angle of attack. Generally, up through this angle the discrepancies in pressure distribution between the $50 \%$ span row and an auxiliary pressure tap row near the hot films are moderate. Above $16^{\circ}$, three-dimensionality becomes more pronounced; hence it may be a contributing factor in results shown below. Details can be found in Bertelrud. ${ }^{47}$

Three-dimensionality affects the data in two ways. First, span-loading variations, which manifest themselves as variations in effective angle of attack, cause the locations of suction peaks and stagnation points to be displaced in the chord-wise direction. Second, separated or low-shear regions, as well as brackets, etc., may cause spanwise flow that alters the transition data. Assuming experimental data are available, the upper surface chordwise effects may be accounted for in the CFD, at least in part, by relating the transition to the distance downstream of the suction peak as opposed to using an absolute geometric location. However, for all the McDonnell Douglas cases in this paper, this is not necessary because the computed suction peak locations agree with those in the experiment to within a distance less than the densest pitch of the hot films. Spanwise effects are not easily accounted for.

Transition locations are determined based on information from 359 surface hot films on the three elements. The start and end of transition are extracted from an analysis of a combination of standard deviation, skewness, and flatness factors of the hot film signals, plus in most cases an additional examination of the signal traces for auto- or cross-correlations. Note that even though the films are located at $2.54 \mathrm{~mm}$ pitch (or $\Delta s / c=0.0045$ ) in the most dense regions, the flows at higher angles of attack have fairly short transition regions, so that only one or two films pick up the feature.

Table 1 Hot film transition data for 30P-30N configuration, $M=0.2$, Re $=9$ million

\begin{tabular}{ccccc}
\hline \hline & \multicolumn{2}{c}{$8 \mathrm{deg}$} & \multicolumn{2}{c}{$19 \mathrm{deg}$} \\
\hline SLAT & $\mathrm{s} / \mathrm{c}$ & $\mathrm{x} / \mathrm{c}$ & $\mathrm{s} / \mathrm{c}$ & $\mathrm{x} / \mathrm{c}$ \\
\hline lower suct peak & $\mathrm{n} / \mathrm{a}$ & & $\mathrm{n} / \mathrm{a}$ & \\
lower trans S & $\mathrm{n} / \mathrm{a}$ & & $\mathrm{n} / \mathrm{a}$ & \\
lower trans E & $\mathrm{n} / \mathrm{a}$ & & $\mathrm{n} / \mathrm{a}$ & \\
upper suct peak & .015 & -.084 & .006 & $-.0852 \mathrm{~L}$ \\
upper trans S & .030 & -.077 & .010 & -.0853 \\
upper trans E & .060 & -.057 & .020 & -.082 \\
\hline \hline MAIN & $\mathrm{s} / \mathrm{c}$ & $\mathrm{x} / \mathrm{c}$ & $\mathrm{s} / \mathrm{c}$ & $\mathrm{x} / \mathrm{c}$ \\
\hline lower suct peak & -.510 & .526 & -.620 & .635 \\
lower trans S & -.405 & .422 & -.670 & .685 \\
lower trans E & -.510 & .526 & $\mathrm{n} / \mathrm{a}$ & \\
upper suct peak & .000 & .0496 & .008 & .055 \\
upper trans S & .012 & .058 & .016 & .061 \\
upper trans E & .025 & .068 & .025 & .068 \\
\hline FLAP & $\mathrm{s} / \mathrm{c}$ & $\mathrm{x} / \mathrm{c}$ & $\mathrm{s} / \mathrm{c}$ & $\mathrm{x} / \mathrm{c}$ \\
\hline lower suct peak & $\mathrm{n} / \mathrm{a}$ & & $\mathrm{n} / \mathrm{a}$ & \\
lower trans S & $\mathrm{n} / \mathrm{a}$ & & $\mathrm{n} / \mathrm{a}$ & \\
lower trans E & $\mathrm{n} / \mathrm{a}$ & & $\mathrm{n} / \mathrm{a}$ & \\
upper suct peak & .026 & .888 & .024 & .886 \\
(mid) & & & & \\
upper suct peak & .020 & .882 & .016 & .878 \\
(aux) & & & & \\
upper trans S & .030 & .892 & .030 & .892 \\
upper trans E & .070 & .931 & .060 & .921 \\
\hline \hline
\end{tabular}

Table 1 lists the starting and ending transition locations for the 30P-30N configuration at two angles of attack, along with locations of the suction peaks. Results are given both in terms of the surface coordinate $s / c$ (where $s / c=0$ corresponds to the location on the forward part of each element in the stowed position where 
$y / c=0)$ as well as the deployed $x / c$ coordinate. Depending on location, the data are accurate to between $\Delta s / c= \pm 0.002-0.005$. Possible film sheet influence on transition has not been taken into account. An " $n / a$ " for the transition start $(S)$ or end $(E)$ indicates that a definitive start or end to transition, respectively, was not detected prior to the cusp on the lower surfaces of the slat and main elements or prior to the trailing edge on the flap. The "L" for the upper suction peak at $19^{\circ}$ indicates that the location is actually on the lower side of the element when the slat is in its rotated position.

Note the discrepancy present in the location of the flap suction peak between the 50\%-span station (mid) and the auxiliary station near the hot films at 73.4\%-span (aux) at both angles of attack. Computed suction peaks agree best with the "mid" data. This table represents only a subset of the transition location measurements taken. A complete set of more than 50 cases, including different Reynolds numbers, Mach numbers, and flap settings as well as more details of the experimental database, can be found in Bertelrud ${ }^{47}$ and Bertelrud et al. ${ }^{48}$

\section{DESCRIPTION OF THE COMPUTER CODE}

The computer code CFL3D ${ }^{49,50,51,52}$ solves the threedimensional time-dependent thin-layer (in each coordinate direction) Reynolds-averaged Navier-Stokes equations with an upwind finite-volume formulation. It can solve flows over multiple-zone grids that are connected in a one-to-one, patched, or overset manner, and can employ grid sequencing, multigrid, and local time stepping when accelerating convergence to steady state. Upwindbiased spatial differencing is used for the inviscid terms, and flux limiting is used to obtain smooth solutions in the vicinity of shock waves, when present. Viscous terms are centrally differenced. The flux-differencesplitting (FDS) method of Roe ${ }^{53}$ is employed to obtain fluxes at the cell faces.

The CFL 3D code is advanced in time with an implicit three-factor approximate factorization method. The implicit derivatives are written as spatially first-order accurate, which results in block tridiagonal inversions for each sweep. However, for solutions that utilize FDS the block tridiagonal inversions are further simplified with a diagonal algorithm (with a spectral radius scaling of the viscous terms). Further details of the CFL3D computer code are not given here; they can be found in the cited references. CFL3D has been used previously to compute 2D multi-element airfoil flow fields with generally good success. 24,42

When free-air grids are used, a far-field point vortex correction $^{54}$ is applied at the outer boundary. This correction has a significant impact, particularly on the computed drag for multi-element airfoil flows. ${ }^{12}$ When internal flow on a grid with walls is computed, the inflow total pressure and total temperature are specified according to isentropic flow relations, and the outflow back pressure is set to obtain the desired inflow Mach number.

\section{TURBULENCE MODELING}

The $S-A^{36}$ one-equation and $S_{S T}{ }^{41}$ two-equation eddy-viscosity turbulence models employed in this study are documented in their respective references. However, the S-A model has a further modification to improve convergence by preventing $\tilde{S}$ from going neg- ative, suggested by $P$. Spalart in a private communication (March 1993), that

$$
\tilde{S}=f_{v 3} S+\frac{\tilde{v}}{\kappa^{2} d^{2}} f_{v 2}
$$

where

$$
\begin{gathered}
f_{v 2}=\left(1+\frac{\chi}{c_{v 2}}\right)^{-3} \\
f_{v 3}=\frac{\left(1+\chi f_{v 1}\right)\left(1-f_{v 2}\right)}{\chi}
\end{gathered}
$$

and $c_{v 2}$ is taken as 5 . The SST model has also been modified slightly from its original form. Details are given in Menter and Rumsey. ${ }^{55}$ (Note that there is an error in equation 17 in that reference. It should read:

$$
\Gamma=\max \left(2 \Gamma_{3} ; \Gamma_{1}\right)
$$

Also, in equation 1 in that reference, the terms $\sigma^{*} \mu_{t}$ and $\sigma \mu_{t}$ should be replaced by $\mu+\sigma^{*} \mu_{t}$ and $\mu+\sigma \mu_{t}$, respectively.)

The Gatski-Speziale explicit algebraic stress model ${ }^{45}$ (EASM) represents an effective compromise between the full second-moment closure and a two-equation eddy-viscosity model. It extracts an algebraic relationship between the turbulent Reynolds stress and the mean velocity field by assuming equilibrium hypotheses on both the convective and diffusive terms of the Reynolds stress transport equation. The EASM model was first implemented in CFL3D by Abid et $\mathrm{al}^{56}$ in both $k-\omega$ and $k-\varepsilon$ form. Further modifications to the model have been made since that time. ${ }^{57}$ For all the results in this paper, the model is implemented in $k-\omega$ formulation as follows.

$$
\begin{aligned}
& \frac{D k}{D t}=P_{k}-\omega k+\frac{1}{\rho} \frac{\partial}{\partial x_{j}}\left[\left(\mu+\frac{\mu_{t}^{*}}{\sigma_{k}}\right) \frac{\partial k}{\partial x_{j}}\right] \\
& \frac{D \omega}{D t}=P_{\omega}-\beta \omega^{2}+\frac{1}{\rho} \frac{\partial}{\partial x_{j}}\left[\left(\mu+\frac{\mu_{t}^{*}}{\sigma_{\omega}}\right) \frac{\partial \omega}{\partial x_{j}}\right]
\end{aligned}
$$

where the production terms are:

$$
\begin{gathered}
P_{k}=-\tau_{i j} \frac{\partial u_{i}}{\partial x_{j}} \\
P_{\omega}=\Upsilon \frac{\omega}{k}\left(-\tau_{i j} \frac{\partial u_{i}}{\partial x_{j}}\right)
\end{gathered}
$$

and $\quad \sigma_{k}=1.4, \quad \sigma_{\omega}=2.2, \quad \beta=0.83$, $\Upsilon=\beta-\left[\kappa^{2} /\left(\sigma_{\omega} \sqrt{c_{\mu}{ }^{*}}\right)\right]$, and $\kappa=0.41$. The equilibrium eddy viscosity term employed in the diffusion terms of equations (5) and (6) is given by

$$
\mu_{t}^{*}=c_{\mu} * \frac{\rho k}{\omega}
$$


where $c_{\mu}{ }^{*}=0.081$.

The explicit nonlinear constitutive equation that is used to close the Reynolds-averaged Navier-Stokes equations is given (after regularization) by

$$
\begin{aligned}
& \rho \tau_{i j}=\frac{2}{3} \rho k \delta_{i j}-2 \mu_{t}\left(S_{i j}-\frac{1}{3} S_{k k} \delta_{i j}\right)- \\
& \frac{2 \mu_{t}^{\prime} \alpha_{3}}{\omega}\left(S_{i k} W_{k j}+S_{j k} W_{k i}\right)+\frac{4 \mu_{t}^{\prime} \alpha_{2}}{\omega}\left(S_{i k} S_{k j}-\frac{1}{3} S_{k l} S_{k l} \delta_{i j}\right)
\end{aligned}
$$

The turbulent viscosity $\mu_{t}$ is

$$
\mu_{t}=c_{\mu} \frac{\rho k}{\omega}
$$

and

$$
\begin{gathered}
c_{\mu}=\frac{3\left(1+\eta^{2}\right)+0.2\left(\eta^{6}+\zeta^{6}\right)}{3+\eta^{2}+6 \zeta^{2} \eta^{2}+6 \zeta^{2}+\eta^{6}+\zeta^{6}} \alpha_{1} \\
\eta=\frac{\alpha_{2}}{\omega}\left(S_{i j} S_{i j}\right)^{1 / 2} \\
\zeta=\frac{\alpha_{3}}{\omega}\left(W_{i j} W_{i j}\right)^{1 / 2}
\end{gathered}
$$

and $\quad \alpha_{1}=\left(4 / 3-C_{2}\right)(g / 2), \quad \alpha_{2}=\left(2-C_{3}\right)(g / 2)$, $\alpha_{3}=\left(2-C_{4}\right)(g / 2)$, and $g=\left(C_{1} / 2+C_{5}-1\right)^{-1}$. The constants governing the Speziale-Sarkar-Gatski (SSG) pressure-strain correlation model ${ }^{58}$ are: $C_{1}=6.8$, $C_{2}=0.36, C_{3}=1.25, C_{4}=0.4$, and $C_{5}=1.88$.

The $\mu_{t}^{\prime}$ terms in equation (10) are given by

$$
\mu_{t}^{\prime}=c_{\mu}{ }^{\prime \rho} \frac{}{\omega}
$$

where

$$
c_{\mu}^{\prime}=\frac{3\left(1+\eta^{2}\right)}{3+\eta^{2}+6 \zeta^{2} \eta^{2}+6 \zeta^{2}+\eta^{6}+\zeta^{6}} \alpha_{1}
$$

\section{RESULTS AND DISCUSSION}

Results are computed for both the AGARD and the McDonnell Douglas configurations. Three turbulence models - S-A, SST, and EASM - are used for the former, but only S-A and EASM are used for the latter.

\subsection{AGARD Configuration}

For the AGARD configuration, surface pressure coefficients and boundary layer total pressure coefficient profiles are compared with experiment ${ }^{11}$ at two corrected angles of attack of $4.01^{\circ}$ and $20.18^{\circ}$. The effect of transition is not assessed for this configuration. Computations are performed with transition set at $x / c=0.125$ on the main element upper and lower surface, and with the slat and flap computed "fully turbulent." The implications of these transition settings will be discussed in the context of the McDonnell Douglas configuration in section 6.2.1.

Computed surface pressure coefficients are compared

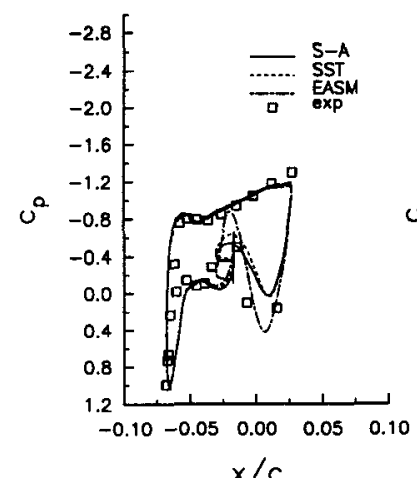

(a) slat

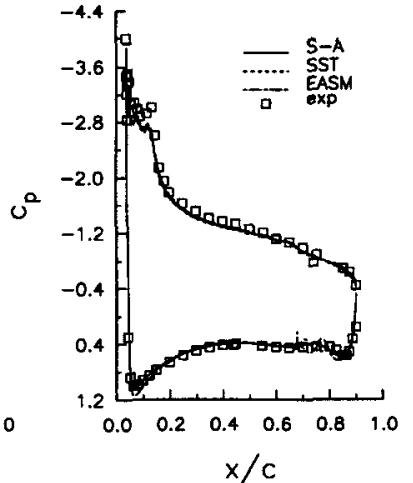

(b) main

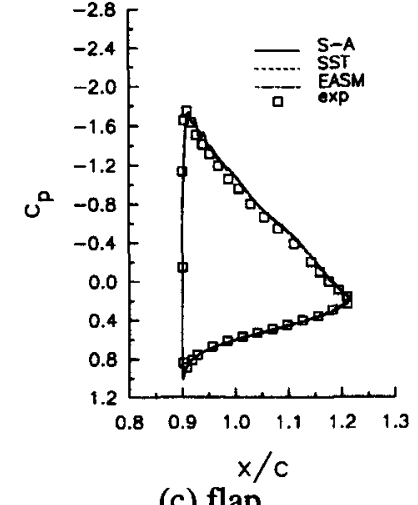

(c) flap

Fig. 3. AGARD surface pressure coefficient, alpha $=4,01^{\circ}$.

with experimental results at an angle of attack of $4.01^{\circ}$ in figures $3(a)-(c)$. On the flap and the main element, all three turbulence models predict $c_{p}$ for this case in good agreement with experimental levels. On the slat, all three models predict $c_{p}$ in good agreement with experiment over the upper surface, and EASM yields significantly different pressures from the other two models in the cove region, closer to experiment.

A similar comparison of surface pressure coefficients at a higher angle of attack of $20.18^{\circ}$ is shown in figures 4(a) - (c). In this case, all turbulence models yield similar results, in good agreement with the experimental results.

Boundary layer profiles of total pressure coefficient are given at $x / c=0.35$ on the upper surface of the main element, as well as at three stations on the upper surface of the flap, as shown in figure 5. Results are shown for the $4.01^{\circ}$ case in figures $6(a)-(d)$, and for the $20.18^{\circ}$ case in figures 7(a) - (d). The parameter $d$ in the figures represents the normal distance from the airfoil surface. At the lower angle of attack, all three models give similar results, in good agreement with experiment, with the exception that EASM predicts more mixing between the flap boundary layer and main element wake than experiment or the other models. Also, the computations with all three turbulence models show evidence of a slat wake whereas the experiment does not. It is interesting to note that even though EASM shows different slat cove $c_{p}$ predictions in figure 3(a), its slat wake does not exhibit much difference from the other models.

At the higher angle of attack, all of the models miss 


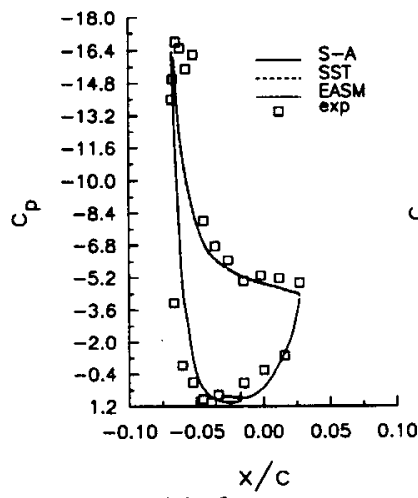

(a) slat

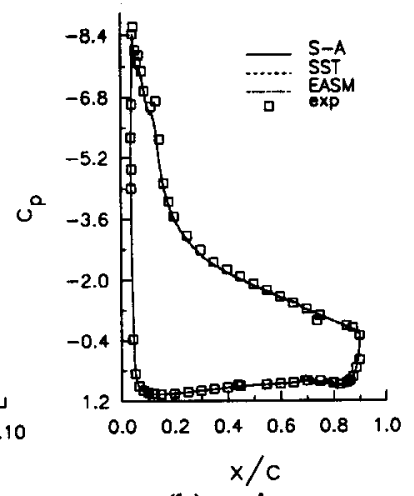

(b) main

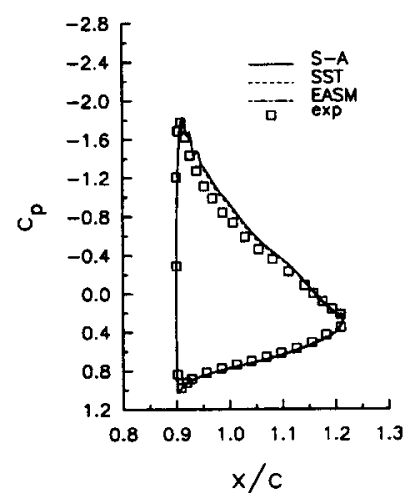

(c) flap

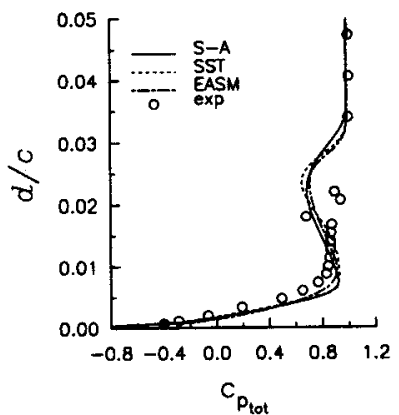

(a) $\mathrm{x} / \mathrm{c}=0.35$ (main)

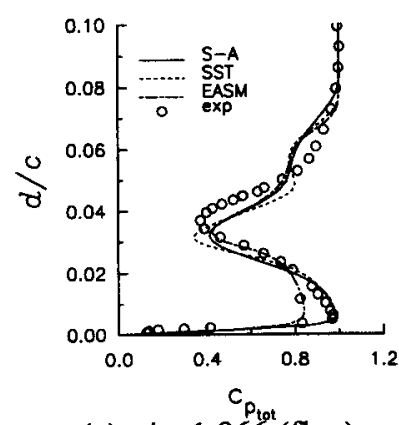

(c) $x / c=1.06$ toft $^{\text {(flap) }}$

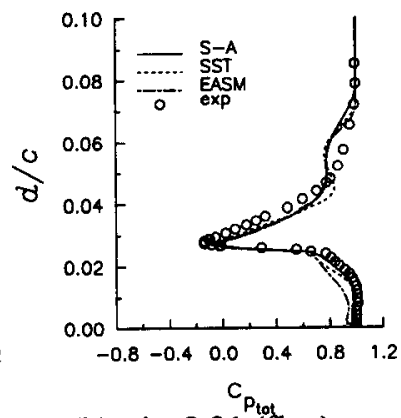

(b) $\mathrm{x} / \mathrm{c}=0.91$ (flap)

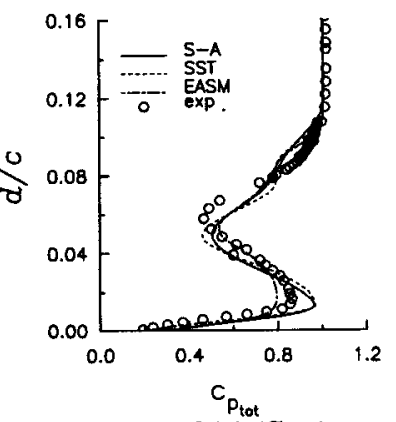

(d) $x / c=1.214$ (flap)

Fig. 6. AGARD total pressure coefficient profiles, alpha $=4.01^{\circ}$.

Fig. 4. AGARD surface pressure coefficient, alpha $=20.18^{\circ}$.

the locations of the main and slat wake at the two aftmost stations on the flap. However, as will be shown in section 6.2.2, modeling the wind tunnel walls has a large effect on the velocity profiles over the flap when the multi-element airfoil is at high angle of attack: computations with walls included tend to shift the wake locations upward. This tendency would improve the current predictions. There are also small differences in total pressure coefficient levels for the three turbulence models there; in particular, EASM yields a deeper slat wake deficit than the other two models, while SST yields a deeper main-element wake deficit.

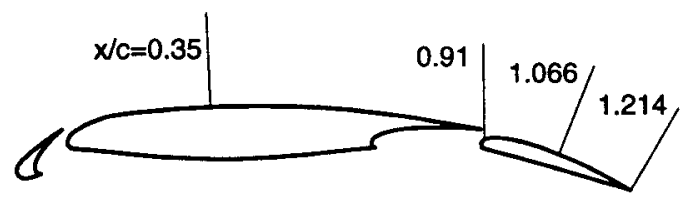

Fig. 5. AGARD profile locations.

Results for this configuration indicate that, while there are minor variations between the three turbulence models, all produce very similar surface pressure and boundary layer total pressure predictions in general. Lift, drag, and moment coefficient over the range of angle-of-attack through maximum lift are also predicted

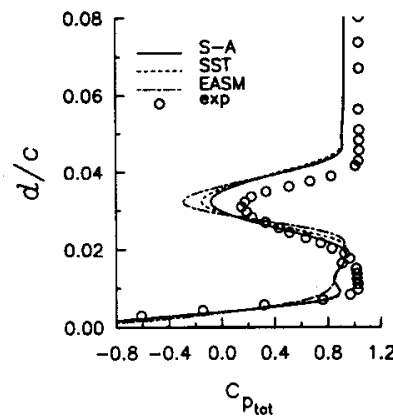

(a) $\mathrm{x} / \mathrm{c}=0.35$ (main)
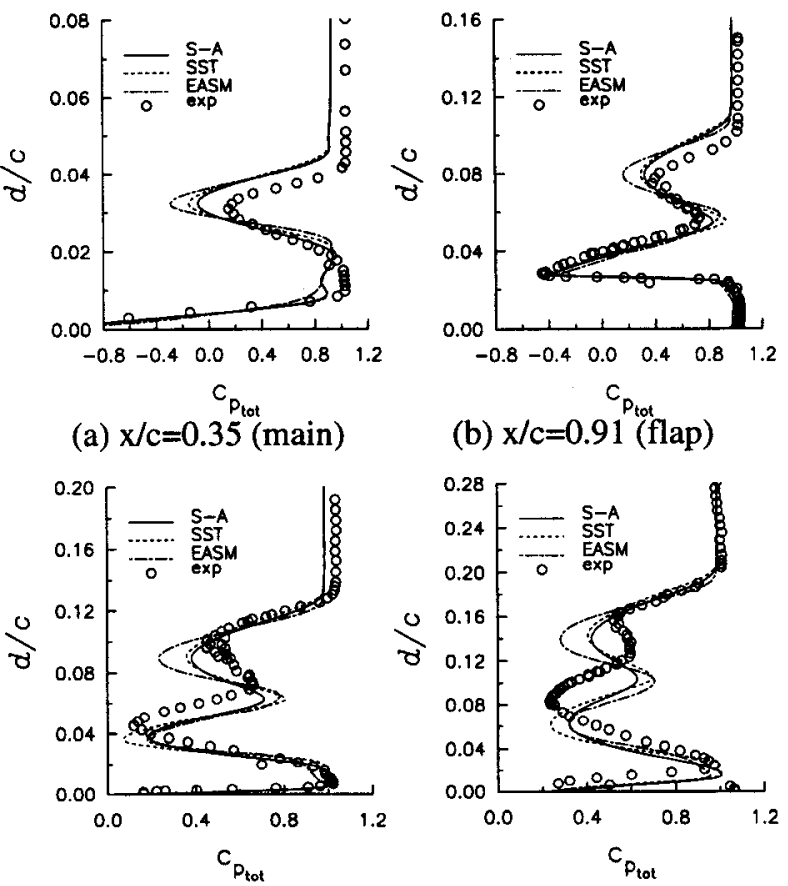

(c) $x / c=1.066$ (flap)

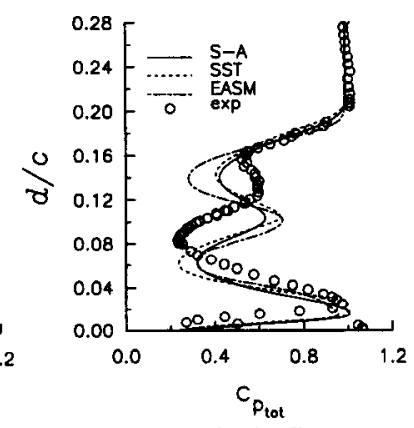

(d) $x / c=1.214$ (flap)

Fig. 7. AGARD total pressure coefficient profiles, alpha $=$ 20.18 ${ }^{\circ}$. 


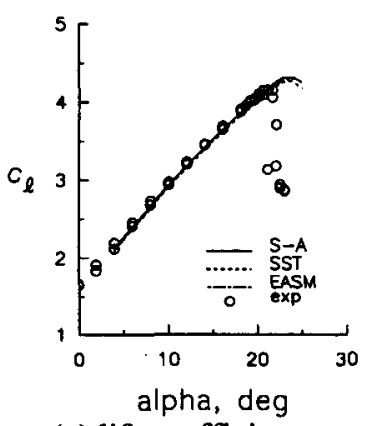

(a) lift coefficient

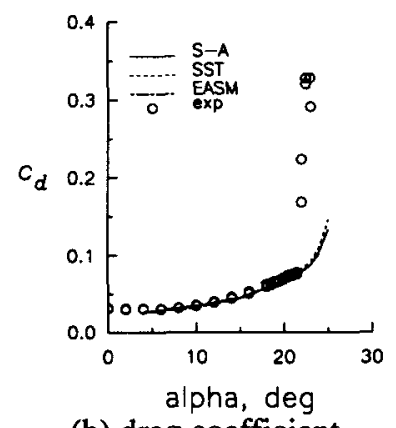

(b) drag coefficient

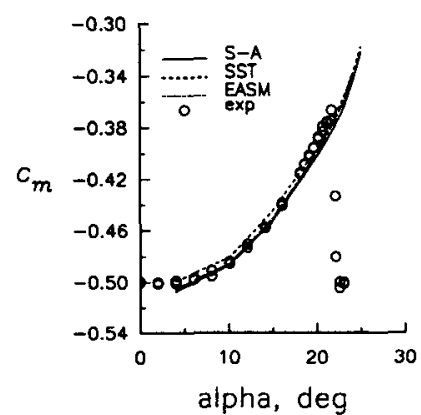

(c) moment coefficient

Fig. 8. AGARD integrated force coefficients.

similarly by the three turbulence models for this case, as shown in figures $8(a)-(c)$. The CFD integrated quantities compare well with experiment over a large range of angles of attack, but computations overpredict the maximum lift coefficient and the angle at which it occurs. The computations also do not exhibit slat separation or the rapid drop-off of lift past $C_{L \max }$ typical of take-off configurations with leading-edge stall. ${ }^{2}$ The drag and moment coefficients also do not agree with experiment at the highest angles of attack past stall.

\subsection{McDonnell Douglas Configuration}

Most of the following results use the McDonnell Douglas 30P-30N landing configuration at an angle of attack of $19^{\circ}$, although some results are also given for a lower angle of attack of $8^{\circ}$. It should be stressed that the hot film data and the pressure, velocity, and skin friction data were taken in independent wind tunnel tests. ${ }^{15-17,47}$ Velocity profiles are given at the locations shown in figure 9. When transition locations are set according to the experimental data of Table 1, they are assumed to be at the ending locations from the hot film data. One exception to this is on the slat upper surface at an angle of attack of $19^{\circ}$. In this case, placing the CFD transition at the ending location results in separation, since the laminar boundary layer cannot negotiate the severe adverse pressure gradient. (Although not shown, this result has also been confirmed with computations using a finer embedded grid around the slat nose, as well as with computations using an independent boundary layer code. The result is also the same whether or not tunnel walls are modeled in the CFD.) Therefore, transition is instead placed as far downstream as possible such that the laminar boundary layer on the slat does not separate.

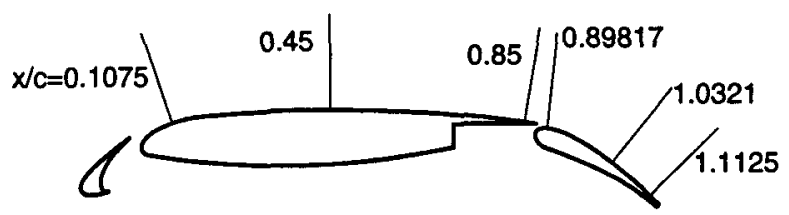

Fig. 9. 30P-30N profile locations.

\subsubsection{Effect of Transition Locations}

The effect of transition locations is explored using the S-A turbulence model on the free-air grid only. It is very important to remember that the CFL3D code does not employ any transition modeling. The code merely zeroes out the production terms in the turbulence model equations in the regions where laminar flow is desired. There is no transition state at all; the turbulence production is either "off" or "on." (Turbulence transport and diffusion are always active, however.) This transition procedure is different from the "trip source term" procedure employed by Spalart and Allmaras. ${ }^{36}$ The current method is used to maintain consistency between the different turbulence models in CFL3D.

It is also important to realize that although "fully turbulent" solutions are accomplished with the production terms of the turbulence models active everywhere, this does not necessarily guarantee that a turbulent boundary layer will exist as far forward as the stagnation point. Instead, in a "fully turbulent" solution, the models essentially transition on their own. In other words, the solution to the turbulence equations results in eddy viscosity levels which may or may not be large enough to create a turbulent boundary layer profile. Generally, at high Reynolds numbers the "fully turbulent" computations result in transition locations well forward of the locations seen experimentally. For example, at $19^{\circ}$ the locations where the S-A model transitions on its own are listed in Table 2. (Transition is assumed to occur when the maximum eddy viscosity level nondimensionalized by molecular viscosity $\mu_{t} / \mu_{\infty}$ in the boundary layer first exceeds unity.) Stagnation points on the lower surfaces of the slat and main elements are $x / c=-0.031$ and 0.154 , respectively. The "fully turbulent" transition locations are all well forward of the experimental regions from Table 1.

Table 2 "Fully turbulent" transition $\mathrm{x} / \mathrm{c}$ locations for $\mathrm{S}$-A model on $30 P \cdot 30 \mathrm{~N}$ configuration, $M=0.2, R e=9$ million, alpha $=19^{\circ}$.

\begin{tabular}{ccc}
\hline \hline transition & $\mathrm{x} / \mathrm{c}, \mathrm{S}-\mathrm{A}$ fully turbulent & $\begin{array}{c}\mathrm{x} / \mathrm{c} \text { range, } \\
\text { from Table } 1\end{array}$ \\
\hline SLAT lower & -.034 & $\mathrm{n} / \mathrm{a}-\mathrm{n} / \mathrm{a}$ \\
SLAT upper & $-.051 \mathrm{~L}$ & $-.0853--.082$ \\
\hline MAIN lower & .177 & $.685-\mathrm{n} / \mathrm{a}$ \\
MAIN upper & $.125 \mathrm{~L}$ & $.061-.068$ \\
\hline FLAP lower & turbulent everywhere & $\mathrm{n} / \mathrm{a}-\mathrm{n} / \mathrm{a}$ \\
FLAP upper & turbulent everywhere & $.892-.921$ \\
\hline \hline
\end{tabular}




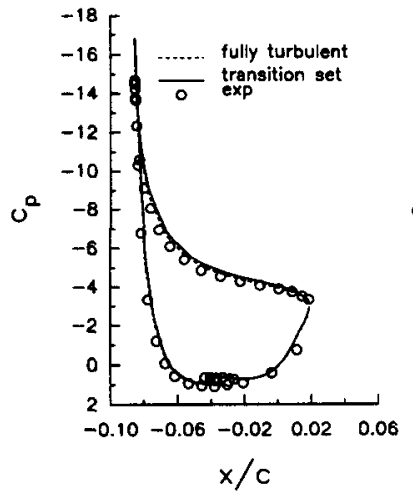

(a) slat

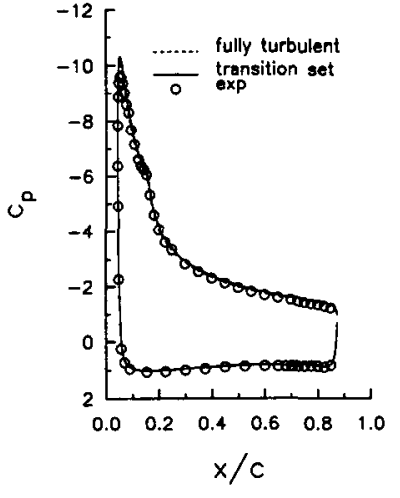

(b) main

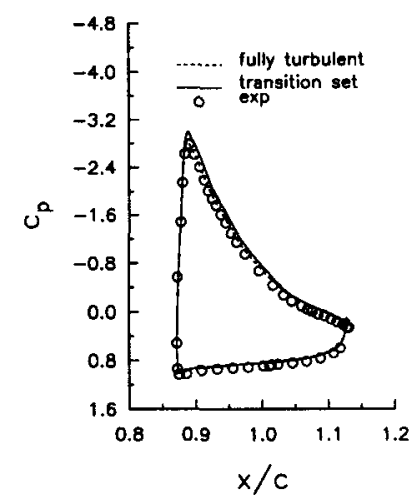

(c) flap

Fig. 10. Effect of transition location on 30P-30N surface pressure coefficient, S-A model on free-air grid, alpha $=19^{\circ}$.

Figures 10(a) - (c) show surface pressure coefficients on each of the elements for both the fully turbulent solution as well as a solution for which the transition on each of the elements is specified according to the experimental data in Table 1, as discussed above. Both computed results are in good agreement with experiment, ${ }^{15,17}$ with only small variations evident on the upper surfaces between the fully-turbulent and transition-specified results. As pointed out in section 1.1, the multi-element interactions largely manipulate the inviscid flow; therefore it is not surprising that transition location has only a small effect on the surface pressures. However, these small variations in pressure translate to a difference in lift coefficient of about 0.12 , of the same order of magnitude as experimental differences in lift coefficient due to flap rigging changes that wing designers would like to predict with CFD. ${ }^{1}$ Also, as will be shown next, the velocity field is quite sensitive to transition location. Because viscous effects are a contributing factor to skin friction forces, possible boundary layer separation, and the stall process governed by the unloading of the aft end of the main element, it is clearly important to predict boundary layer and wake profiles accurately.

To compute the boundary layer and wake thickness correctly over the main element, transition locations must be set correctly: This effect is demonstrated for the upper surface in figures 11 (a) and (b). The velocity profiles at the stations $x / c=0.45$ and $x / c=0.89817$ are shown for the main element fully turbulent versus main element with upper surface transition set close to the transition-ending location from Table 1 . The slat and flap are both fully turbulent in this case. When the main element is fully turbulent, its boundary layer profile (below "slat wake" in figure 11(a)) is too thick compared with experiment. ${ }^{15}$ When transition is set, the profile below the slat wake agrees better. The part of the wake due to the main element upper surface boundary layer (upper part of "main wake" in figure 11(b)) is also better predicted with transition specified. In addition, the computed skin friction coefficient on the main element, although still low at the $x / c=0.45$ station, is in better agreement with experiment ${ }^{16}$ when the transition is set, as seen in figure 12 .

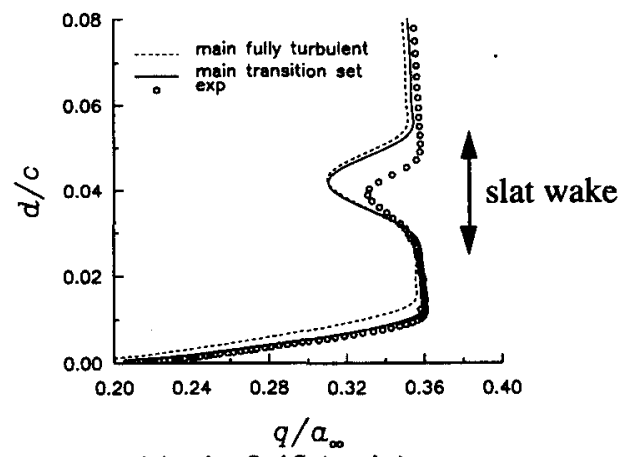

(a) $\mathrm{x} / \mathrm{c}=0.45$ (main)

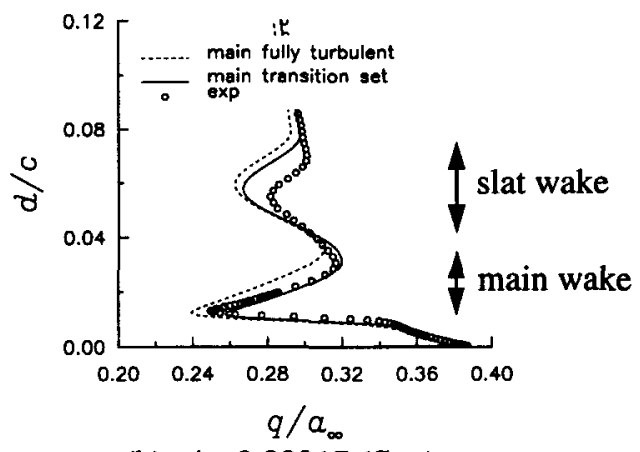

(b) $\mathrm{x} / \mathrm{c}=0.89817$ (flap)

Fig. 11. Effect of main element transition location on 30P-30N velocity profiles, S-A model on free-air grid, alpha $=19^{\circ}$.

In figures $11(a)$ and (b), when the slat is fully turbulent the slat wake is predicted to be too wide and deep. Because it is likely that the slat transition location has a large influence on the slat wake structure over the downstream elements, we next turn our attention to an investigation of its effect. Both the upper and lower surfaces of the slat contribute to the shape of the slat wake. However, since the lower surface has the added complication of separated flow followed by reattachment in the cove, we focus our attention solely on the effect of upper surface transition location. The lower surface transition is set at the cusp for all cases shown here.

Unfortunately, the upper surface transition location on the slat cannot be pushed further downstream than approximately $x / c=-0.0847$, while still maintaining 


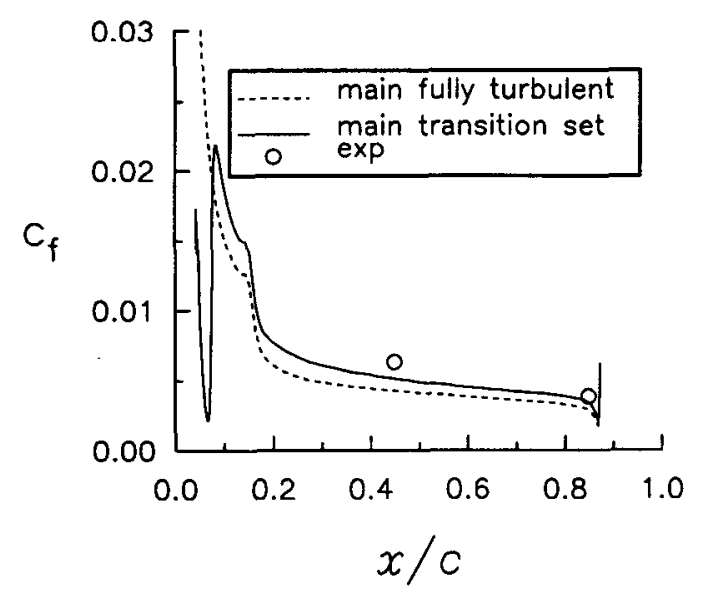

Fig. 12. Efiect of main element transition location on 30P-30N upper surface main element skin friction, $S$-A model on free-air grid, alpha $=19^{\circ}$.

an attached laminar boundary layer (experimental transition range from Table 1 is $x / c=-0.0853$ to -0.082 ). To effectively force transition further downstream, we employ suction over a small region on the slat in the computations to prevent the laminar boundary layer from separating. Computed velocity profiles are shown in figures $13(\mathrm{a})-(\mathrm{c})$. In these figures, the locations $\mathrm{A}$, $B$, and $C$ correspond with $x / c=-0.0847$, $x / c=-0.082$, and $x / c=-0.073$, respectively. Their locations relative to the starting and ending locations from Table 1 are shown in figure 14 . Wake velocity profiles that result from transition at location $C$ agree best with experimental profiles, although there are still differences between computation and experiment, particularly in the slat wake / main boundary layer merging region at $x / c=0.85$. In the notation of Squire, ${ }^{32}$ (discussed in section 1.3), this latter station is in the region of initial merging, whereas the first two stations are in the unmerged regime. Note that transition location $\mathrm{C}$ is downstream of the experimentally-measured transition location region.

Even at the first station $x / c=0.1075$ (figure 13(a)), which is on the main element just aft of the slat trailing edge, the wakes predicted using fully turbulent, A, or B have deficits and thicknesses that are too large. (The offset velocity difference between computation and experiment in this figure is probably a result of improper calibration in the experimental data, as suggested by $F$. Spaid in a private communication (May 1997)). Using location $\mathrm{C}$, the computed slat wake width and deficit roughly agree with experiment at this first station as well as over the entire length of the main element. This indicates that (ignoring the wake / boundary layer merging region at $x / c=0.85$ for now) the $S$-A turbulence model can do a fairly good job representing the wake development itself, given a good initial profile. Therefore, poor agreement of the slat wake with experiment may not be due to any particular failure of the turbulence model in modeling the wake, but rather the fact that the computed boundary layer leaving the slat is wrong to start with.

At a lower angle of attack of $8^{\circ}$, the experiment ${ }^{15}$ indicates an extremely diffuse slat wake at and beyond

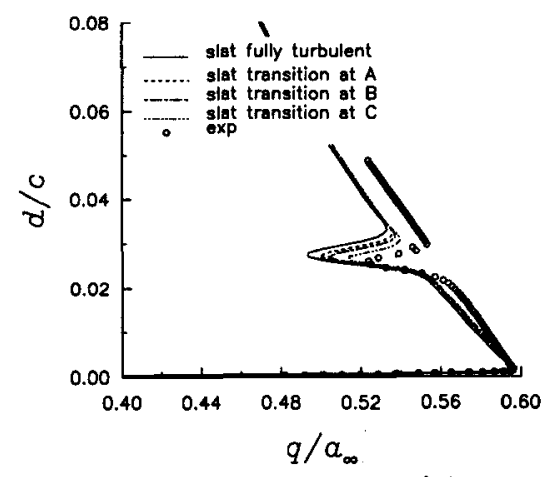

(a) $x / c=0.1075$ (main)

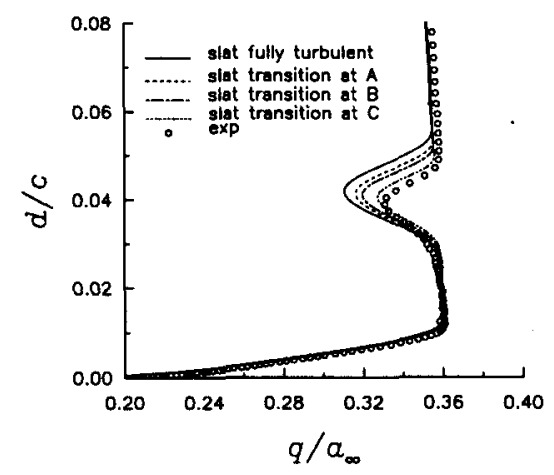

(b) $x / c=0.45$ (main)

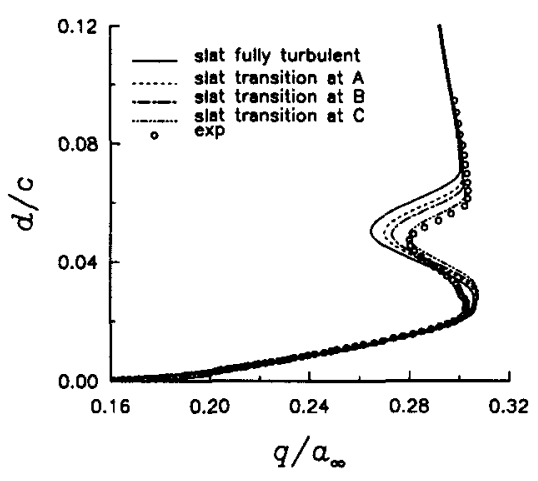

(c) $x / c=0.85$ (main)

Fig. 13. Effect of slat transition location on $30 \mathrm{P}-30 \mathrm{~N}$ velocity profiles, S-A model on free-air grid, alpha $=19^{\circ}$.

$x / c=0.45$, whereas computations do not. Velocity profiles are shown in figures $15(\mathrm{a})$ and (b) at the first two stations of the main element only (results at $x / c=0.85$ are similar). When the slat is fully turbulent, the computed slat wake is too deep and wide at the first station $x / c=0.1075$, and remains so further downstream. However, even moving the slat transition location to $\mathrm{D}(x / c=-0.056$, which is the approximate ending location of transition from the experiment) or to $\mathrm{E}(x / c=0.015$, near the slat trailing edge) still results in too large a wake deficit. (In this case, boundary layer suction is not necessary to move the transition location downstream, since the adverse pressure gradient is not too severe for the laminar boundary layer to handle.) It therefore appears that the computations over the slat may again be incorrect by the time they leave the slat 


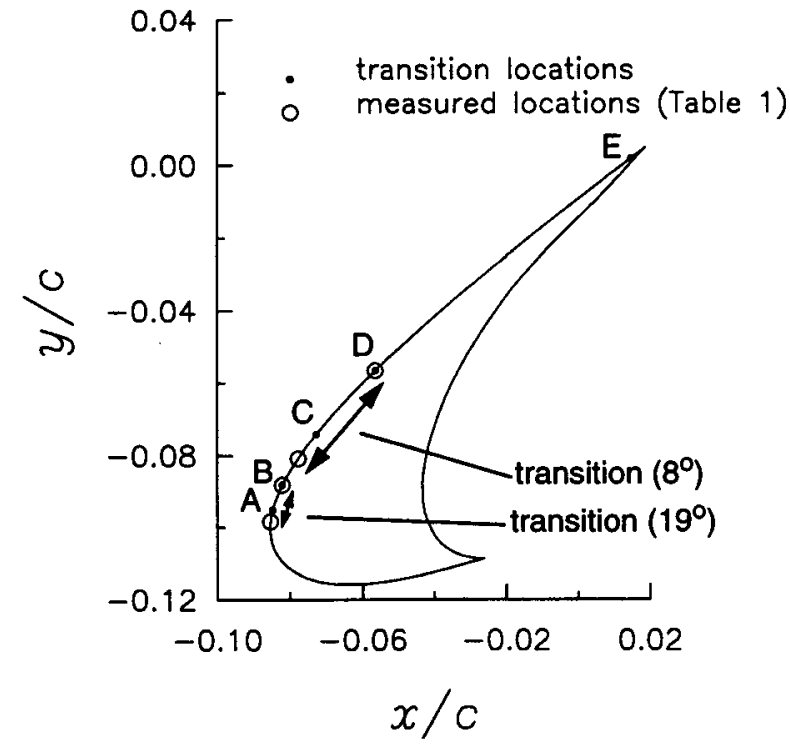

Fig. 14. 30P-30N upper surface slat transition locations.

trailing edge. At this angle of attack, however, no upper surface slat transition location provides satisfactory slat wake profiles in good agreement with experiment. Although not shown, results are similar using EASM.

At this time, it is not known what physical processes on the slat are not being modeled correctly in the computations. Although we strongly suspect that the primary cause is related to transition (upper and/or lower surface transition locations, transition modeling, laminar bubble modeling, possible transition in the cove free-shear layer, etc.), it is also possible that $3 \mathrm{D}$ effects or possibly unsteady effects resulting from the slat-cove separated flow are contributing factors. Certainly inadequate turbulence modeling in the wake may be a contributing factor as well, but there is no evidence at this time to point to its being a primary source of error. Determining the actual causes will be difficult because there are almost no experimental flow field data over the slat itself at this high Reynolds number. It will also be difficult to draw conclusions about the ability of turbulence models to accurately predict processes such as slat wake / boundary layer merging until we are confident that the slat flow field, and consequently its initial wake profile, are computed adequately to start with.

\subsubsection{Effect of Turbulence Model}

For the remainder of the computations in this paper (all at $19^{\circ}$ ), the ending transition locations from the experiment - as given in Table 1 - are used, with the exception mentioned earlier that the slat upper surface transition is placed at $x / c=-0.0847$ to avoid laminar boundary layer separation. No boundary layer suction is employed. However, it is recognized that the flow over the slat is not being modeled correctly; therefore the results are deficient in that regard.

Also, all remaining computations are performed on grids with the tunnel walls modeled. The effect of the tunnel walls using EASM is shown in figures 16(a) (d). The largest effect is on the profiles on the flap,

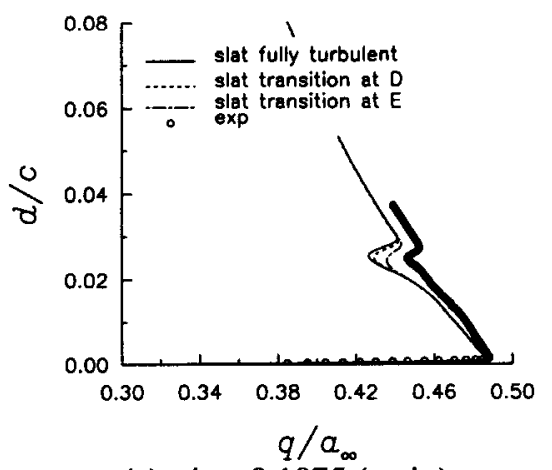

(a) $x / c=0.1075$ (main)

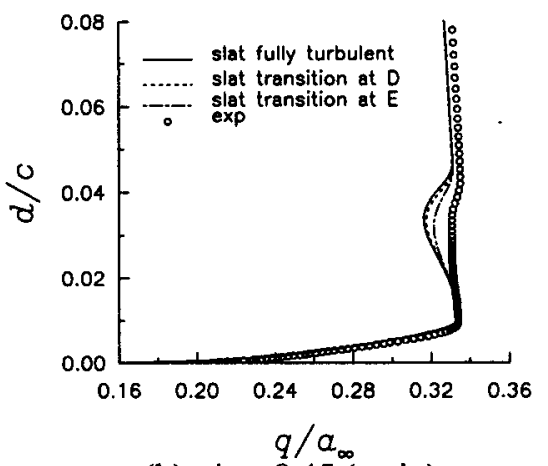

(b) $x / c=0.45$ (main)

Fig. 15. Effect of slat transition location on $30 \mathrm{P}-30 \mathrm{~N}$ velocity profiles, S-A model on free-air grid, alpha $=8^{\circ}$.

where including the walls causes the wakes to be shifted upward because the streamlines are constrained from turning as much. The wake deficits are also, for the most part, deeper when the walls are modeled. These wall effects are consistent with those reported by Cao et al. ${ }^{22}$

Results using the S-A model and EASM are compared in figures 17(a) - (d) and in figures 18(a) - (d). The velocity profiles predicted by the two models are very similar, as are the turbulent shear stress profiles, which are rotated so as to be taken with respect to the directions parallel $\left(u^{\prime}\right)$ and normal $\left(v^{\prime}\right)$ to the body surface. However, EASM tends to give slightly lower peak $u^{\prime} v^{\prime}$ levels over the flap, in general. Also, at the first station on the flap, EASM predicts the peak $u^{\prime} v^{\prime}$ to be deeper in the flap boundary layer than the S-A model. The reason for this shift is currently not known. In spite of this difference, there is very little impact on the computed velocity profiles.

Computations with the S-A model require roughly between $3000-6000$ multigrid cycles to converge, depending on the case and initial conditions, at a CPU cost of approximately $10 \mu \mathrm{s} /$ grid point / multigrid cycle on a single-processor CRAY C90. EASM is more dependent on its initial conditions, and therefore can often require more multigrid cycles to reach convergence, at a CPU cost of approximately $13 \mu \mathrm{s} /$ grid point / multigrid cycle. 


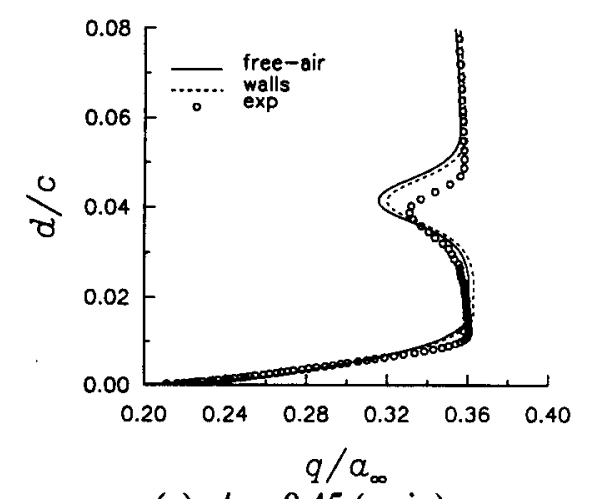

(a) $\mathrm{x} / \mathrm{c}=0.45$ (main)

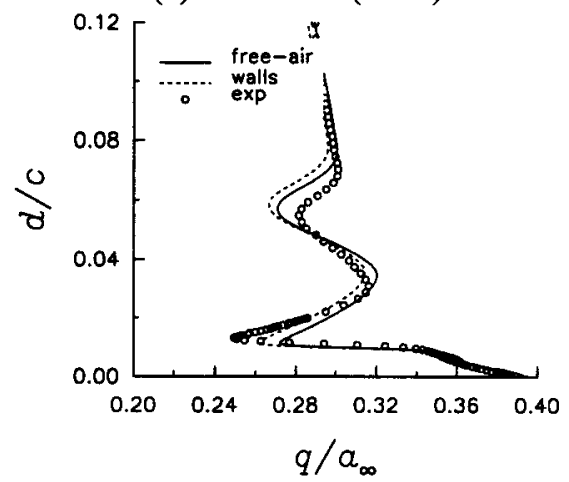

(b) $x / c=0.89817$ (flap)

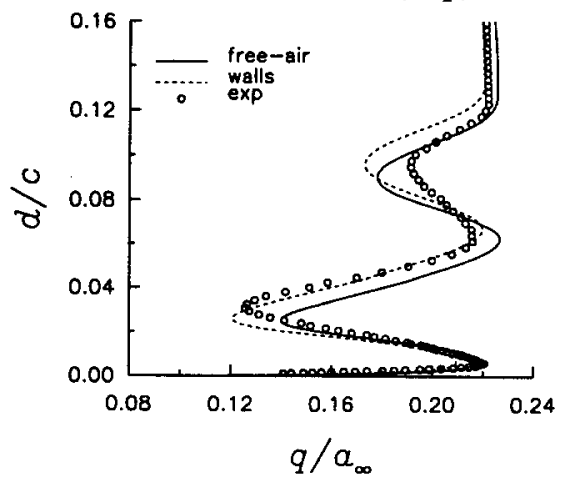

(c) $\mathrm{x} / \mathrm{c}=1.0321$ (flap)

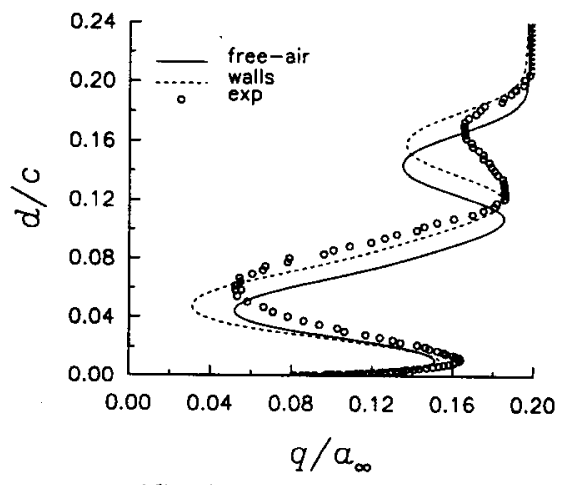

(d) $x / c=1.1125$ (flap)

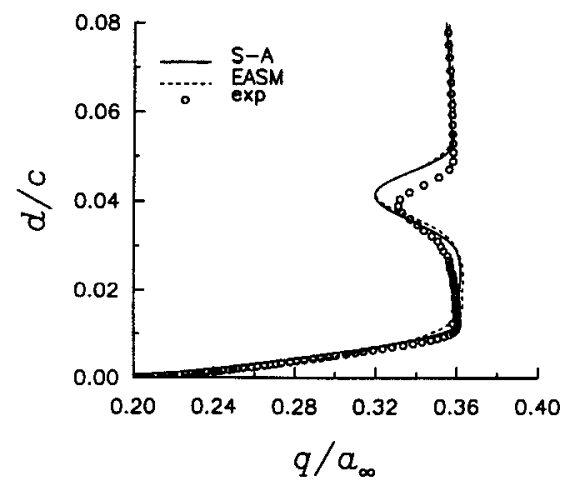

(a) $\mathrm{x} / \mathrm{c}=0.45$ (main)

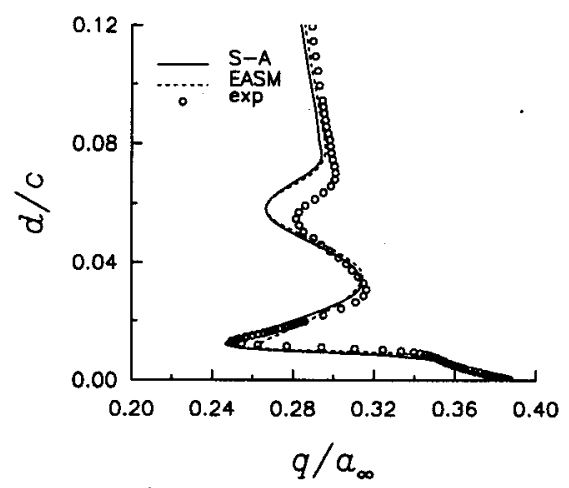

(b) $\mathrm{x} / \mathrm{c}=0.89817$ (flap)

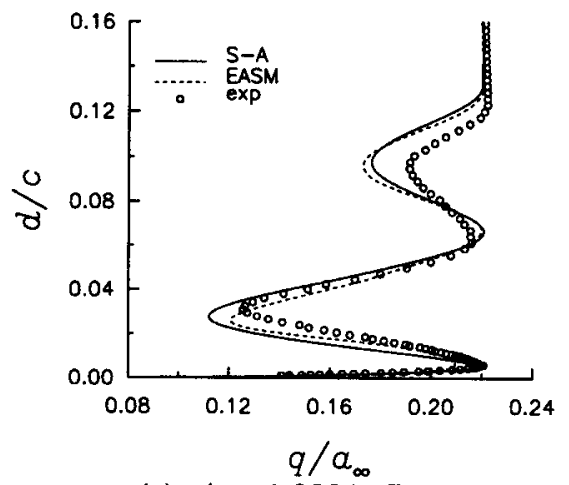

(c) $x / c=1.0321$ (flap)

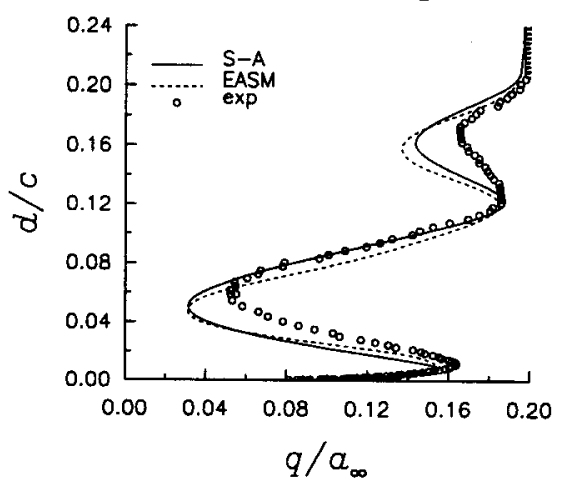

(d) $x / c=1.1125$ (flap)
Fig. 16. Effect of walls on $30 P-30$ N velocity profiles, EASM, transition set, alpha $=19^{\circ}$.
Fig. 17. Effect of turbulence model on $30 \mathrm{P}-30 \mathrm{~N}$ velocity profiles, transition set, walls modeled, alpha $=19^{\circ}$. 


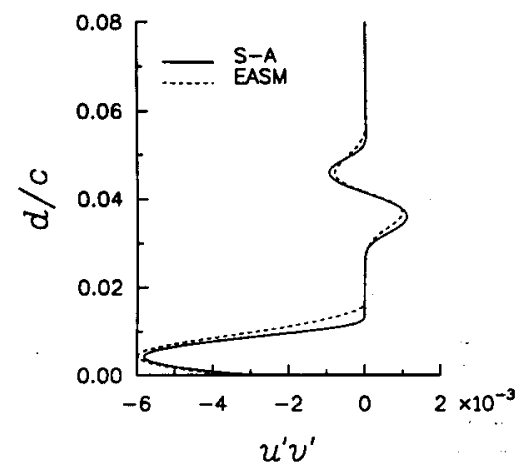

(a) $\mathrm{x} / \mathrm{c}=0.45$ (main)

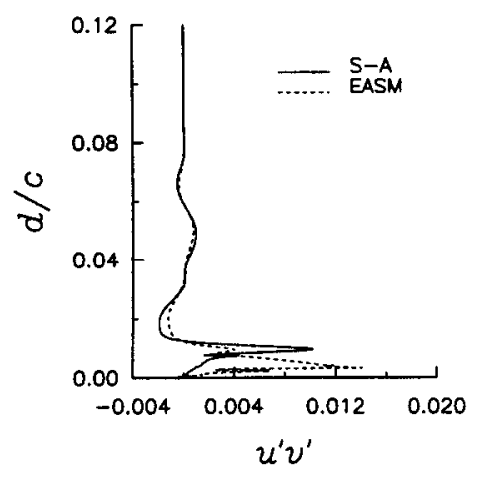

(b) $x / c=0.89817$ (flap)

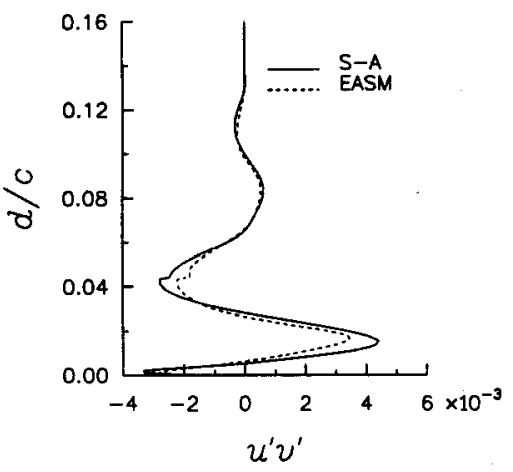

(c) $x / c=1.0321$ (flap)

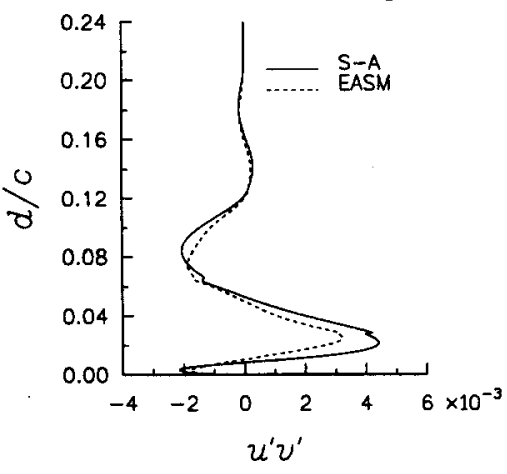

(d) $\mathrm{x} / \mathrm{c}=1.1125$ (flap)

Fig. 18. Effect of turbulence model on $30 \mathrm{P} \cdot 30 \mathrm{~N}$ turbulent shear stress profiles, transition set, walls modeled, alpha $=19^{\circ}$.

\section{CONCLUSIONS}

The flows over two different multi-element airfoil configurations have been computed using linear eddy viscosity turbulence models and a nonlinear explicit algebraic stress model. A subset of recently-measured transition locations using hot film on a McDonnell Douglas configuration has been presented, and the effect of transition location on the computed solutions has been explored. Based on the computed results and comparison with experimental data, the following conclusions are made:

1. Specifying transition location correctly is crucial to the accurate computation of boundary layer velocity profiles. Poor boundary layer profile predictions lead to poor trailing-edge near-wake profile predictions and, therefore, poor predictions in the far wake region. Thus, inadequate wake predictions cannot be attributed solely to inadequate turbulence modeling, but must be attributed in part to deficiencies in transition prediction on the generating element. Recently measured transition locations are helpful in this regard. Using them for the main element improves the prediction of its boundary layer thickness, skin friction, and wake profile shape.

2. The flow field over the slat is not well understood and is difficult to predict. Using the measured transition locations for the slat either results in slat separation or else results in only marginal improvement in slat wake profiles in comparison with experimental data. Possible reasons for this disagreement are: (i) the fact that CFD does not model the transition process itself, which may be more important on the slat than on the other elements, (ii) the hot film array used to measure the transition locations may have some effect on the flow field and possibly the transition locations themselves, and (iii) important slat physics (such as possible 3D effects, laminar separation bubbles, and shear-layer transition and/ or unsteadiness in the cove region) are not being modeled in the computations. Future CFD efforts in this area may be hampered by the fact that detailed experimental flow field measurements can be difficult to obtain in the slat region, particularly at high Reynolds numbers because of the smaller scales. However, since the computation of the slat flow field appears to represent a key roadblock to successful predictions of multi-element flows, some experimental efforts to document the flow physics in this region may be prudent.

3. Although there are some variations, the nonlinear explicit algebraic stress turbulence model overall gives very similar results to linear eddy viscosity turbulence models.

\section{ACKNOWLEDGEMENTS}

The authors thank W. T. Jones of GEOLAB at NASA Langley for generating the McDonnell Douglas configuration grids, and J. B. Anders, Jr. and C. B. McGinley of the Flow Modeling and Control Branch of NASA Langley for their help and useful discussions. The authors also acknowledge S. E. Rogers of NASA Ames, F. W. Spaid of McDonnell Douglas, P. R. Spalart of Boeing, and W. K. Anderson of NASA Langley for their assistance and insightful comments. 


\section{REFERENCES}

'Lynch, F. T., Potter, R. C., and Spaid, F. W., "Requirements for Effective High Lift CFD," ICAS Proceedings, 20th Congress, September 1996.

${ }^{2}$ Haines, A. B., "Scale Effects on Aircraft and Weapon Aerodynamics," AGARD-AG-323, July 1994.

'Yip, L. P., Vijgen, P. M. H. W., Hardin, J. D., and VanDam, C. P., "In-Flight Pressure Distributions and Skin-Friction Measurements on a Subsonic Transport High-Lift Wing Section," AGARD-CP-515, September 1993, pp. 21.1 - 21.19.

${ }^{4}$ Kirkpatrick, D. and Woodward, D., "Priorities for High-Lift Testing in the 1990's," AIAA Paper 90-1413, June 1990.

5Ying, S. X., "High Lift: Challenges and Directions for CFD," AIAANPU AFM Conference proceedings, China, June 1996.

'Meredith, P. T., "Viscous Phenomena Affecting High-Lift Systems and Suggestions for Future CFD Development," AGARD-CP-515, September 1993, pp. $19.1-19.8$.

${ }^{7}$ Smith, A. M. O., "High Lift Aerodynamics," Journal of Aircraft, Vol. 12, No. 6, 1975, pp. 501 - 530.

${ }^{8}$ Woodward, D. S. and Lean, D. E., "Where is High Lift Today? - A Review of Past UK Research Programmes," AGARD-CP-515, September 1993, pp. 1.1 -1.45 .

${ }^{9}$ Thibert, J. J., Reneaux, J., Moens, F., and Preist, J., "ONERA Activities on High-Lift Devices for Transport Aircraft," Proceedings of Royal Aeronautical Society High Lift and Separation Control Meeting, March 1995, pp. 5.1 - 5.18 .

10Valarezo, W. O., "Topics in High-Lift Aerodynamics," AIAA Paper 93-3136, July 1993.

"Burt, M., "A Selection of Experimental Test Cases for the Validation of CFD Codes: Chapter 5 - Summaries of the Test Cases," AGARD AR-303, Vol. 1, August 1994, pp. $55-133$.

${ }^{12}$ Fejtek, I., "Summary of Code Validation Results for a Multiple Element Airfoil Test Case," AIAA Paper 97-1932, July 1997.

${ }^{13}$ Stainback, P. C., McGhee, R. J., Beasley, W. D., and Morgan, H. L. Jr., "The Langley Research Center's Low Turbulence Pressure Tunnel," AIAA Paper 860762, March 1986.

${ }^{14}$ Paschal, K., Goodman, W., McGhee, R., Walker, B., and Wilcox, P. A., "Evaluation of Tunnel Sidewall Boundary-Layer-Control Systems for High-Lift Airfoil Testing," AIAA Paper 91-3243, September 1991.

${ }^{15}$ Spaid, F. W. and Lynch, F. T., "High Reynolds Number Multi-Element Airfoil Flowfield Measurements," AIAA Paper 96-0682, January 1996.

${ }^{16}$ Klausmeyer, S. M. and Lin, J. C., "An Experimental Investigation of Skin Friction on a Multi-Element Airfoil," AIAA Paper 94-1870, June 1994.

${ }^{17}$ Chin, V. D., Peters, D. W., Spaid, F. W., and McGhee, R. J., "Flowfield Measurements About a Multi-Element Airfoil at High Reynolds Numbers," AIAA Paper 93-3137, July 1993.
${ }^{18}$ Valarezo, W. O., Dominik, C. J., and McGhee, R. J., "Reynolds and Mach Number Effects on Multielement Airfoils," Proceedings of 5th Symposium on $\mathrm{Nu}$ merical and Physical Aspects of Aerodynamic Flows, California State University at Long Beach, January 1992.

${ }^{19}$ Valarezo, W. O., Dominik, C. J., McGhee, R. J., Goodman, W. L., and Paschal, K. B., "Multi-Element Airfoil Optimization for Maximum Lift at High Reynolds Numbers," AIAA Paper 91-3332-CP, 1991.

${ }^{20}$ Rogers, S. E., "Progress in High-Lift Aerodynamic Calculations," AIAA Paper 93-0194, January 1993.

${ }^{21}$ Dominik, C. J., "Application of the Incompressible Navier-Stokes Equations to High-Lift Flows," AIAA Paper 94-1872, June 1994.

${ }^{22}$ Cao, H. V., Kusunose, K., Spalart, P. R., Ishimitsu, K. K., Rogers, S. E., and McGhee, R. J., "Study of Wind Tunnel Wall Interference for Multi-Element Airfoils Using a Navier-Stokes Code," AlAA Paper 941933, June 1994.

${ }^{23}$ Kusunose, K. and Cao, H. V., "Prediction of Transition Location for a 2-D Navier-Stokes Solver for MultiElement Airfoil Configurations," AIAA Paper 94-2376, June 1994.

${ }^{24}$ Jones, K. M., Biedron, R. T., and Whitlock, M., "Application of a Navier-Stokes Solver to the Analysis of Multielement Airfoils and Wings Using Multizonal Grid Techniques," AIAA Paper 95-1855, June 1995.

${ }^{25}$ Valarezo, W. O. and Mavriplis, D. J., "NavierStokes Applications to High-Lift Airfoil Analysis," AIAA Paper 93-3534, August 1993.

${ }^{26}$ Anderson, W. K., Bonhaus, D. L., McGhee, R. J., and Walker, B. S., "Navier-Stokes Computations and Experimental Comparisons for Multielement Airfoil Configurations," Journal of Aircraft, Vol. 32, No. 6, 1995, pp. 1246 - 1253.

${ }^{27} \mathrm{CaO}, \mathrm{H}$. V., and Kusunose, K., "Grid Generation and Navier-Stokes Analysis for Multi-Element Airfoils," AIAA Paper 94-0748, January 1994.

${ }^{28}$ Kusunose, K. and Cao, H. V., "Numerical Prediction of Reverse Reynolds Number Effects for Multi-Element Airfoils," 9th International Conference on $\mathrm{Nu}$ merical Methods in Laminar and Turbulent Flow, Atlanta, GA, July 1995.

${ }^{29}$ Cebeci, T., "Calculation of Multielement Airfoils and Wings at High Lift," AGARD-CP-515, September 1993, pp. 24.1 - 24.15.

${ }^{30}$ Arlinger, B. G., Larsson, T., Arnold, F., Earnshaw, P. B., Moens, F., Saliveros, E., and Termes, A. P. P., "Reynolds- and Mach-Number Effects and 2D-3D Correlation Based on Measurements and Computed Results for the GARTEUR Take-Off Configuration," Proceedings of Royal Aeronautical Society High Lift and Separation Control Meeting, March 1995, pp. 26.1 - 26.15.

${ }^{31}$ Rogers, S. E., Menter, F. R., Durbin, P. A., and Mansour, N. N., "A Comparison of Turbulence Models in Computing Multi-Element Airfoil Flows," AIAA Paper 94-0291, January 1994. 
${ }^{32}$ Squire, L. C., "Interactions Between Wakes and Boundary Layers," Prog. Aerospace Sci., Vol. 26, 1989, pp. 261 - 288.

${ }^{33}$ Agoropoulos, D. and Squire, L. C., "Interactions Between Turbulent Wakes and Boundary Layers," AIAA Journal, Vol. 26, No. 10, 1988, pp. 1194 - 1200.

${ }^{34}$ Anderson, W. K. and Bonhaus, D. L., "NavierStokes Computations and Experimental Comparisons for Multielement Airfoil Configurations," AIAA Paper 93-0645, January 1993.

${ }^{35}$ Nakayama, A., Kreplin, H. P., and Morgan, H. L., "Experimental Investigation of Flowfield About a Multielement Airfoil," AIAA Journal, Vol. 28, No. 1, 1990, pp. $14-21$.

${ }^{36}$ Spalart, P., and Allmaras, S., "A One-Equation Turbulence Model for Aerodynamic Flows," La Recherche Aerospatiale, Vol. 1, 1994, pp. 5 - 21.

${ }^{37}$ Lien, F. S. and Leschziner, M. A., "Modelling 2D Separation from a High Lift Aerofoil with a Non-Linear Eddy-Viscosity Model and Second-Moment Closure," Aeronautical Journal of the Royal Aeronautical Society, April 1995, pp. 125 - 144.

${ }^{38}$ Lien, F. S., Chen, W. L., and Leschziner, M. A., "Computational Modelling of High-Lift Aerofoils with Turbulence-Transport Models," Proceedings of Royal Aeronautical Society High Lift and Separation Control Meeting, March 1995, pp. 10.1 - 10.14.

${ }^{39}$ Van den Berg, B., "Boundary Layer Measurements on a Two-Dimensional Wing with Flap," National Aerospace Lab., NLR TR 79009 U, Amsterdam, The Netherlands, January 1979.

${ }^{40}$ Godin, P., Zingg, D. W., and Nelson, T. E., "HighLift Aerodynamic Computations with One- and TwoEquation Turbulence Models," AIAA Journal, Vol. 35, No. 2, 1997, pp. 237 - 243.

${ }^{41}$ Menter, F. R., "Improved Two-Equation k- $\omega$ Turbulence Models for Aerodynamic Flows," NASA TM 103975, October 1992.

${ }^{42}$ Jasper, D. W., Agrawal, S., and Robinson, B. A., "Navier-Stokes Calculations on Multi-Element Airfoils Using a Chimera-Based Solver," AGARD-CP-515, September 1993, pp. 8.1 - 8.11.

${ }^{43} F$ ritz, W., "Calculation of Maximum and High Lift Characteristics of Multi Element Airfoils," AGARDCP-515, September 1993, pp. 5.1 - 5.12.

${ }^{44}$ Kral, L. D., Mani, M., and Ladd, J. A., "On the Application of Turbulence Models for Aerodynamic and Propulsion Flowfields," AIAA Paper 96-0564, January 1996.

${ }^{45}$ Gatski, T. B. and Speziale, C. G., "On Explicit Algebraic Stress Models for Complex Turbulent Flows," J. Fluid Mech., Vol. 254, 1993, pp. 59 - 78.

${ }^{46}$ Nakayama, A., Stack, J. P., Lin, J. C., and Valarezo, W. O., "Surface Hot-Film Technique for Measurements of Transition, Separation, and Reattachment Points," AIAA Paper 93-2918, July 1993.

${ }^{47}$ Bertelrud, A., "Documentation of Transition on a Three-Element High-Lift Configuration at High Reynolds Numbers - Analysis," NASA CR-201700, 1997.
48Bertelrud, A., Johnson, S., Lytle, C., and Mills, C., "A System for Analysis of Transition Characteristics on a High-Lift Configuration at High Reynolds Numbers," to appear at the 17th ICIASF, September 1997, Monterey, CA.

${ }^{49}$ Thomas, J. L., Krist, S. L., and Anderson, W. K., "Navier-Stokes Computations of Vortical Flows Over Low Aspect-Ratio Wings," AIAA Journal, Vol. 28, No. 2, 1990, pp. $205-212$.

${ }^{50}$ Vatsa, V. N., Thomas, J. L., and Wedan, B. W., "Navier-Stokes Computations of Prolate Spheroids at Angle of Attack," Journal of Aircraft, Vol. 26, No. 11, 1989, pp. 986 - 993.

51Thomas, J. L., "Reynolds Number Effects on Supersonic Asymmetrical Flows over a Cone," Journal of Aircraft, Vol. 30, No. 4, 1993, pp. 488 - 495.

${ }^{52}$ Rumsey, C. L., Sanetrik, M. D., Biedron, R. T., Melson, N. D., and Parlette, E. B., "Efficiency and Accuracy of Time-Accurate Turbulent Navier-Stokes Computations," Computers and Fluids, Vol. 25, No. 2, 1996, pp. 217 - 236.

${ }^{53}$ Roe, P., "Approximate Riemann Solvers, Parameter Vectors, and Difference Schemes," Journal of Computational Physics, Vol. 43, 1981, pp. 357 - 372.

${ }^{54}$ Thomas, J. L. and Salas, M. D., "Far-Field Boundary Conditions for Transonic Lifting Solutions to the Euler Equations," AIAA Journal, Vol. 24, No. 7, 1986, pp. $1074-1080$.

${ }^{55}$ Menter, F. R. and Rumsey, C. L., "Assessment of Two-Equation Turbulence Models for Transonic Flows," AIAA Paper 94-2343, June 1994.

${ }^{56}$ Abid, R., Rumsey, C. L., and Gatski, T. B., "Prediction of Nonequilibrium Turbulent Flows with Explicit Algebraic Stress Models," AIAA Journal, Vol. 33, No. 11, 1995, pp. $2026-2031$.

${ }^{57}$ Gatski, T. B., "Prediction of Airfoil Characteristics with Higher Order Turbulence Models," NASA TM 110246, April 1996.

${ }^{58}$ Speziale, C. G., Sarkar, S., and Gatski, T. B., "Prediction of Nonequilibrium Turbulent Flows with Explicit Algebraic Stress Models," AIAA Journal, Vol. 33, No. 11, 1995, pp. 2026 - 2031. 